the flame was in the same way independent of the conductivity of the flame.

At the close of the meeting of the section on Wednesday morning, September 12, votes of thanks to the president and secretaries were passed, and the section adjourned to Glasgow.

C. H. LEES.

\section{ASTRONOMY AT THE BRITISH}

\section{ASSOCIATION.}

A STRONOMY this year constituted a distinct department of Section A, with its own chairman and secretaries, and a separate room was provided for the reading of papers on this subject. The new departure was sufficiently justified by the attendance at the meetings, and in future years, when the formation of the Department of Astronomy becomes more widely known, increased success may be confidently expected. The department met on Friday, September 7, and Tuesday, September II, and altogether sixteen papers were read.

At Friday's meeting, after the chairman's address, three papers by Prof. Todd, relating to eclipse work, were read by one of the secretaries in the absence of the author. In one of these attention was called to the "application of the electric telegraph to the furtherance of eclipse research." In 1878 , the idea first occurred to Prof. Todd to telegraph eastward in advance of the lunar shadow in order to enable the immediate verification of any possible discovery, as of an intramercurian planet, without waiting for another eclipse. The feasibility of the method was demonstrated in January 1889 , and again more completely during the eclipse of May 28, 1900. At the station occupied by Mr. Douglas in Georgia, totality preceded the same phenomena in Tripoli, where Prof. Todd himself was observing, by $2 \mathrm{~h} .45 \mathrm{~m}$., and the outcome of the experiment was that, through the generous help afforded by the various telegraph companies, an account of the American observations was received by Prof. Todd more than two hours before totality occurred at Tripoli. Abundant time for special preparations to verify any important discovery was thus available.

In his second paper Prof. Todd dealt with a variety of methods of operating eclipse instruments automatically. The "mechanical system," as distinct from the pneumatic and electric arrangements which he had previously devised, was first tried during the recent eclipse. The instruments being set up on the roof of the British Consulate, gravity was utilised for the meshanical operation of slides and shutters. One hundred photographs were secured at Tripoli by seven instruments operated in this manner. Experience indicates that the gravity method is the best where the number of instruments is not great.

Another paper by Prof. Todd described the use of a wedge of yellow optical glass in giving correctly graduated exposures of the partial phases and corona on a single biograph film.

An important paper on the classification of sun-spots was read by the Rev. A. L. Corti, S. J, and illustrated by a fine series of lantern slides selected from the thousands of drawings made at Stonyhurst during the last twenty years. Five types, with a certain number of sub-divisions, were found sufficient to denote the characters of all the spots which had so far been examined.

The chief type, of which the others are probably but phases, is the two-spot formation. The faculæ associated with the different types are also of different characters, and it may be pos. sible to foretell the outburst of a spot by the observation of a certain kind of facula. As an illustration of the use of the type numbers, the life-history of a composite disturbance which crossed the solar disc five times between May 14 and September 4,1887 , was thus described:-

\section{I., II. $b \mid$ IV. $d$, IV. $a \mid$ IV. $a$, IV. $d$, IV. $a \mid$ IV. $a$, I., II. $a \mid$ I.}

In the course of the discussion on this paper it became evident that the need for some short system of notation had long been felt by observers of sun-spots, and that, providing the scheme suggested would cover all cases, it would be very valuable. The chairman remarked that possibly a still better system, which would tax the memory less, might be devised on the plan of Herschel's notation for nebulæ.

Prof. Turner exhibited and explained " a cheap form of micrometer for determining star positions on photographic plates." The essential features are a wooden frame to support the photograph, with an attachment carrying a simple microscope containing a scale in the eye-piece. For less than thirty shillings an efficient instrument can be constructed, capable of yielding measures of practical utility. It thus becomes possible for any one to undertake inmportant researches at a much smaller outlay than would be involved in the purchase of a telescope, since there is no lack of material to work upon. Among the investigations mentioned by Prof. Turner as possible with such a machine, were the determination of the positions of nebulæ and comets, and measurements to ascertain the forms of the trails of meteors. Considerable interest in the proposal was displayed, and the hope was expressed that many who now spend their time in fruitless star gazing with small instruments may be induced to undertake these micrometric measurements.

Thursday's meeting was opened with an interesting paper by Dr. Lockyer, in which a comparison was made of the details of the prominences and corona as shown in photographs taken during the recent eclipse at intervals of $2 \frac{1}{2}$ hours, by Prof. Langley and Sir Norman Lockyer, in America and Sprin respectively. While enormous changes in the prominences were revealed, no change was detected in the structure of the corona in the region of the North Pole, which had been specially investigated. An interesting feature of one of the photographs taken in Spain with an exposure of 40 seconds was the extreme hardness of the moon's limb, notwithstanding the relative motion of the moon during the exposure; the explanation of this unexpected appearance was based on the rapid diminution in intensity of the corona as the outer layers are reached, so that the momentary exposures of the lower corona on the advancing limb of the moon at the beginning of the exposure, and on the following limb at the end, were sufficient to give a strong impression.

The new form of refracting telescope recently erected at Cambridge, chiefly for photographic work, was described by Mr. A. R. Hinks, and illustrated by lantern slides. The objectglass is a Taylor triple lens of $12 \frac{1}{2}$ inches aperture, and the chief peculiarity of the mounting is that the portion which is usually the lower half of the tube forms the polar axis, with the eye-end at the top, while the object-glass end is hinged to the other piece, and a plane mirror is placed at the junction. In another paper Mr. Hinks referred to the preparations which are being made for determining the solar parallax by observations of Eros during the coming winter, and exhibited a series of diagrams showing the path of the Cambridge Observatory as seen from that planet at various times. With the aid of such diagrams the observer can see at a glance the most favourable times for making micrometric measurements or taking photographs for the purpose in hand. The importance of the observations of Eros was emphasised by Prof. Turner, who remarked that at the present time the probable error of the adopted value of the solar parallax was equivalent to the thickness of a wicket in the length of a cricket pitch. Unlike the transit of Venus, the observations of Eros would be easily reduced, and the results of the observations would soon be accessible.

A paper on "some points in connection with the photography of a moving object," by Mr. W. E. Plummer, had an important bearing on the photographic method of ascertaining the position of such a rapidly moving object as the planet Eros. A com. parison of measurements of the positions of a comet made with a micrometer and those determined from photographs indicated that considerable errors might be introduced in the photographic results on account of the difficulty of determining the epoch of observation. Since the first few moments of exposure on the moving object leave no impression, the middle of the trail does not correspond to the middle of the exposure. In exposures of ten minutes on Eros the danger of error was very considerable. Mr. Hinks remarked that it was hoped to ubtain sufficiently strong impressions of the field containing Eros with exposures of one or two minutes, under favourable circumstances, and moreover, special precautions to eliminate this difficulty had been arranged at the Paris Conference.

Mr. John Herschel described in detail his method of observing and recording the paths of meteors. Special maps are constructed in which the brighter stars are represented by perfora. tions made with needles of various sizes, the side of the paper away from the observer being blue, while that towards him is white. The map being laid on a sloping desk of ground glass illuminated by a night light, the paths of the meteors are ruled in by means of a transparent celluloid ruler having a black edge.

NO. I6I4, VOL. 62] 
The duration of flight is estimated by repeating the letters of the alphabet, minus $w$, at the rate of five per second, after experience gained from previous practice.

Among other papers presented to the astronomical department was one by Mr. C. T. Whitwell, on "The Duration of Totality of the Solar Eclipse of May 28, 1900." A table which was given illustrated very forcibly the discrepancies between the calculated and observed durations at various observing stations. It was pointed out that to reconcile the observations and calculations by supposing that there were errors in the adopted value of the moon's diameter, or in the position of the observing station, involved the assumption of greater errors than were probable, though each may account in part for the discordance. Another suggestion, due to Mr. Crommelin, was put forward-namely, that, on account of the irregularities of the moon's limb, the beginning of totality is retarded by an amount corresponding to the movement of the moon required to bring the lowest depressions to the edge of the sun's disc after the assumed geometrical boundary has made contact, while for a similar reason the end of totality would be hastened.

A. Fowler.

\section{CHEMISTR Y AT THE BRITISH ASSOCIATION.}

A LTHOUGH the president of section B, Prof. W. H. Perkin, junr., is mainly known as a specialist on polymethylene compounds, his address upon the teaching of inorganic chemistry proved to be of very general interest and was enthusiastically received by a large audience. His contention that the present system of examinations would be advantageously superseded by an inspection of the students' laboratory notebooks was favourably commented upon by Sir H. E. Roscoe and Dr. H. E. Armstrong, although it was admitted that the practical difficulties in the way of such a method are very considerable. The presidential address was followed by the report of the committee on the teaching of science in elementary schools, of which Dr. J. H. Gladstone is chairman; the report consisted principally of a discussion of the returns of the Education Department in so far as they concern the teaching of elementary science. The debate which ensued materially assisted the strong case which was subsequently made out in favour of establishing a separate section of the Association for dealing with educationa matters. A paper was next read by Dr. Letts and Mr. R. F. Blake on some problems connected with atmospheric carbonic anhydride and on a new and accurate method for determining its amount, suitable for scientific expeditions; attention was drawn to the variations in the amount of atmospheric carbonic anhydride, and possible explanations of the variations were con sidered. The authors determine carbonic anhydride in air by absorbing it from about six litres with caustic potash solution, subsequently liberating it by boiling the potash solution with acid in a vacuum and measuring the volume of the carbonic anhydride in a suitable eudiometer. Mr. W. Ackroyd contributed papers on the distribution of chlorine in West Yorkshire and on a limiting standard of acidity for moorland waters. Water from the upper reaches of the West Yorkshire rivers contain from 0 " 7 to I' 3 parts of chlorine per IOO,000, but as the sea or a more populous district is approached, the chlorine number becomes much greater. No cases of plumbism have yet been traced to the solvent action upon lead pipes of water of which the acidity is less than the equivalent of 0.5 part of sulphuric acid per 100,000; this acidity value is therefore tentatively proposed as a limiting standard for potable waters of moorland origin. Dr. T. W. Hime read a paper on the effects of copper on the human body, in which he sought to show that the agitation against the use of articles of food containing small quantities of copper salts is unjustifiable, because a large number of well-known food stuffs contain copper as a normal constituent and because such articles of food exert no poisonous action at all. Reports were received from the committees on the bibliography of spectroscopy and on the preparation of a new series of wave-length tables of the spectra of the elements. Prof. H, B. Dixon and Mr. F. W. Rixon, in a paper on the specific heat of gases at temperatures up to $400^{\circ}$, showed an apparatus for making such determinations at constant volume in which a steel cylinder containing the gas is heated and dropped into a calorimeter; the preliminary results obtained with carbonic anhydride were stated. Mr.

F. H. Neville communicated a report on the chemical com- pounds contained in alloys of which the following is a brief abstract. Intermetallic compounds may be compared with the unstable compounds of the halogens with each other and with sulphur ; they often bear a great superficial resemblance to their constituent elements and appear to show marked dissociation, or to form systems in true equilibrium with the liquid mixture of their components.

The intermetallic compounds may be isolated from an alloy (I) by filtration, (2) by volatilisation of excess of a volatile metal, or (3) by removing the excess of metal by means of a suitable solvent. Method (I) has been used by Heycock and Neville who, on filtering a partially solidified solution of gold and cadmium in tin, obtained a crystalline residue having the composition AuCd; method (2) was applied to the preparation of the same compound by distilling the excess of cadmium from an alloy of gold and cadmium. Lebeau prepared the compounds $\mathrm{SbNa}_{3}, \mathrm{BiNa}_{3}$ and $\mathrm{SnNa}_{4}$ by distilling the excess of sodium from alloys in ammonia and nitrogen gas. Debray isolated the compounds $\mathrm{PtSn}_{4}, \mathrm{RhSn}_{3}$ and $\mathrm{RuSn}_{3}$, and Le Chatelier obtained $\mathrm{Cu}_{3} \mathrm{Sn}$ by the action of dilute hydrochloric acid on alloys con taining excess of tin ; by methods of a similar nature Heycock prepared $\mathrm{PtAl}_{3}$ and Stead isolated the crystalline substances $\mathrm{Au}_{4} \mathrm{~Pb}, \mathrm{Au}_{5} \mathrm{~Pb}_{2}, \mathrm{SnSb}$ and $\mathrm{Sn}_{3} \mathrm{As}_{2}$. There is, in the application of this method, considerable risk of the solvent attacking the crystals, and Stead has found that the formation of crystals having a core differing in composition from the outside constitutes a serious drawback to the method of partial solution regarded as an independent method of investigation. In the systematic study of intermetallic compounds may be placed first that of the chemical equilibrium of the binary system; this is generally expressed by the freezing-point curve, and has been mainly investigated by Roozeboom and Le Chatelier. Next, and perhaps of equal importance, is placed the microscopic examination of the solid alloys; whilst thirdly, and more limited in applicability, comes the determination of the difference of electrical potential existing between a metal and its alloys. On determining the freezing-points of a series of mixtures of two metals and plotting the freezing-points as ordinates against the compositions as abscissæ, a freezing-point curve is obtained which in its simplest form consists of two branches meeting at an angle-the eutectic angle-lying at a minimum point on the curve. In other cases the freezing-point curve shows a maximum point, but this is not cusped and lies on a gradual change of curvature; the freezing-point curve may thus consist of a series of branches connected by summits and eutectic depressions. It is pretty generally recognised that the eutectic alloy is merely a conglomerate and not a compound, but it is a remarkable fact that the position of the eutectic point on the curve often corresponds closely with some simple molecular composition; cases of this have been observed, not only with alloys, but also amongst organic compounds, by Paternò and Ampolla. The branches of the curve upon which summits lie are caused by the separation of comp sunds of definite chemical composition from the solidifying magma; the maximum points lie at positions corresponding to the composition of the com. pound, but Le Chatelier considers that the summit does not necessarily lie exactly at the point indicated by the molecular composition, owing to dissociation occurring in the liquid state. This point, however, needs further investigation. The points upon the freezing-point curve merely denote the temperatures at which solid begins to separate from the magma, but Roozeboom has shown that valuable results may be obtained by plotting, not only the temperatures at which solid begins to separate, but also the temperatures at which complete solidification occurs; in general, the one curve lies below the other, but they intersect or become one whenever the alloy solidifies as a whole. The microscopic examination of the pattern shown by the polished surface of an alloy which has, if necessary, been etched or heated to produce oxidation colours has been worked at principally by Osmond, Charpy and Stead. The existence of coated crystals is made evident by this method, as in the case of the bronzes rich in tin, in which Stead has shown that the $\mathrm{Cu}_{3} \mathrm{Sn}$ crystals are coated with CuSn. Le Chatelier has pointed out that in these cases the solid alloy is not in equilibrium, and that annealing will, in general, cause considerable change. Charpy and Stead also consider that evidence of the existence of series of mixed crystals is obtained by microscopic examination. Röntgen ray photographs of thin sections of alloys which contain one transparent metal and one more opaque often give good views of the 